\title{
Addiction is a disease: We must change our attitudes toward addicts
}

$\mathrm{H}$ ealth professionals too often think and behave negatively toward addicts and addiction. In this, we share the attitudes of our society, in which substance abuse is one of the last remaining socially acceptable targets for public discrimination. But we ought to know better. If we are to succeed in treating addiction as a disease which it is - we need to acknowledge and overcome our negative attitudes so that we can help patients with addiction and guide how the public perceives them.

Misconceptions, stigma and ignorance about those who suffer from addiction are widespread. In Canada, these attitudes have gained prominence recently following the Supreme Court's decision to uphold North America's first and only safe injection clinic in Vancouver. ${ }^{1}$ The resulting public discourse revealed popular support on both sides of the issue, but commonly exhibited opinions that addiction is a moral failing and that substance use by addicts is a choice.

That health professionals are by no means free from such attitudes was highlighted saliently by recent research published in CMAJ that illustrated the negative opinions expressed by hospital staff about smoking behaviours of inpatients. ${ }^{2}$ We are all too prone, consciously or subconsciously, to fall back on the prejudices we along with our fellow citizens have naturally acquired. These prejudices lead us to view the behaviours of smokers, alcoholics and other substance users as moral and lifestyle choices, ${ }^{3}$ rather than to see them through the lens of disease biology.

In contrast, there is a large and growing body of evidence about the neurobiologic basis for addiction behaviours, the role of genetic, environmental and epidemiologic factors, and the effectiveness of biologically based interventions for addiction (including harm reduction strategies). This evidence demonstrates that substance use is not a simple matter of choice. People use addictive substances because they generate intense brain responses - reward, craving and withdrawal - mediated by neurotransmitters (particularly dopamine) that potently drive behaviour. ${ }^{4}$ The use of addictive substances also directly causes difficulty with decision-making and with judging the consequences of one's actions by impairing the function of brain areas responsible for cognition (the prefrontal cortex). Stimuli and stressors in a user's environment reinforce addictive behaviour. Many genetic polymorphisms have been identified that enhance addictive responses by altering receptor sensitivity or drug metabolism. Over time, continued substance use causes permanent anatomic and chemical changes in the brain. $^{4}$

Addiction is a chronic relapsing disease that we must treat as we do other such diseases. We do not expect the hearts of patients with heart failure to behave normally — we understand that their function has been altered by disease. Why, then, do we expect the brains of substances abusers to behave normally, since we know that their function has also been altered by disease? We understand how genetic polymorphisms can make cancers resistant to treatment; we are quick to show compassion to patients with such cancers. Why, then, can we not show the same understanding and compassion toward people whose genetic polymorphisms make them resistant to stopping smoking, abusing alcohol or injecting narcotics?

There is room for legitimate debate about what therapeutic and policy interventions should be adopted for addiction. Societal values have a rightful place in this debate. The role played in addiction, as in other diseases, by elements of choice and personal responsibility must also be acknowledged, provided we recognize how addiction itself impairs this role. However, the debate must proceed based on scientific evidence and rational argument, not on myths or political ideology.

Increasing political and scientific interest in how best to deal with addiction will likely continue to fuel broad public discussion. Health professionals are uniquely qualified to inform and influence this discussion. But to do so coherently, let alone effectively, we must first change our own latent discriminatory attitudes. This means consciously training ourselves to think about and behave toward the patients with addiction we encounter on our wards, in our offices and in front of our hospitals in the same way we think about and behave toward other patients. This will be challenging - perhaps as challenging as breaking free from addiction - but only then can we truly deliver appropriate, supportive and professional care to all who struggle with this difficult and often life-destroying problem.

Matthew B. Stanbrook MD PhD

Deputy Editor, $C M A J$

\section{References}

1. Ljunggren D. Safe drug-injection site can stay: Supreme Court of Canada. Reuters Canada, 2011 Sept. 11. Available: http://ca.reuters.com/article/topNews/idCATRE78T2ZE20110930 (accessed 2011 Dec. 2).

2. Schultz AS, Finegan B, Nykiforuk CI, et al. A qualitative investigation of smokefree policies on hospital property. CMAJ 2011;183:E1334-44.

3. Lawn S. Habit or addiction: the critical tension in deciding who should enforce hospital smoke-free policies. CMAJ 2011;183:2085-6.

4. Ross S, Peselow E. The neurobiology of addictive disorders. Clin Neuropharmacol 2009;32:269-76.

Competing interests: See www.cmaj.ca/site/misc/cmaj_staff.xhtml

Correspondence to: CMAJ Editor, pubs@cmaj.ca

CMAJ 2012. DOI:10.1503/cmaj.111957 